\title{
Association between breakfast composition and abdominal obesity in the Swiss adult population eating breakfast regularly
}

Angeline Chatelan ${ }^{1} \mathbb{D}$, Katia Castetbon², Jerome Pasquier ${ }^{1}$, Chloe Allemann ${ }^{1}$, Alexandre Zuber ${ }^{1}$, Esther Camenzind-Frey ${ }^{3}$, Christine Anne Zuberbuehler ${ }^{3}$ and Murielle Bochud ${ }^{1 *}$

\begin{abstract}
Background: Evidence from experimental and observational studies is limited regarding the most favorable breakfast composition to prevent abdominal fat accumulation. We explored the association between breakfast composition (a posteriori derived dietary patterns) and abdominal obesity among regular breakfast eaters from a Swiss population-based sample.
\end{abstract}

Methods: The cross-sectional survey assessed diet using two 24-h dietary recalls in a nationally representative sample of adults aged 18 to 75 years. We derived dietary patterns using principal component analysis based on the intake of 22 breakfast-specific food groups. All regular breakfast eaters were predicted an individual score for each identified pattern, and then classified into tertiles $(T 1, T 2, T 3)$. We defined abdominal obesity as waist-to-hip ratio $(W H R) \geq 0.9$ in men and $\geq 0.85$ in women. Logistic models were adjusted for sociodemographic characteristics, relevant nutrition- and health-related behaviors, and diet quality during the rest of the day.

Results: Of the 2019 included survey participants, 1351 (67\%) were regular breakfast eaters. Among them, we identified three breakfast types: 1) 'traditional' - white bread, butter, sweet spread, 2) 'prudent' - fruit, unprocessed and unsweetened cereal flakes, nuts/seeds, yogurt, and 3) 'western' - processed breakfast cereals, and milk. The 'prudent' breakfast was negatively associated with abdominal obesity. After full adjustment, including diet quality during the rest of the day, the association was weaker (T3 vs. T1: OR $0.72,95 \% \mathrm{Cl}: 0.47$ to 1.08). People taking a 'prudent' breakfast (in T3) had 1.2\% lower WHR compared to people taking a breakfast distant from 'prudent' (in T1) $(P=0.02$, fully adjusted model with continuous log-WHR). We found no association between 'traditional' or 'western' breakfasts and WHR (OR 1.00, 95\% Cl: 0.67 to 1.50 and OR 1.16, 95\% Cl: 0.79 to 1.71, respectively). Findings were in the same directions for the three breakfast types when defining obesity with waist circumference, waist-to-height ratio, or body mass index ( $\geq 30 \mathrm{~kg} / \mathrm{m}^{2}$, for 'prudent' breakfast: OR $0.51,95 \% \mathrm{Cl}: 0.31$ to 0.85 ).

Conclusions: Regular breakfast consumers had less abdominal obesity if their breakfast was composed of fruit, natural cereal flakes, nuts/seeds and yogurt. This association was partly explained by their healthier diet during the rest of the day.

Trial registration: ISRCTN16778734.

Keywords: National nutrition survey, menuCH, Breakfast, Dietary pattern, Abdominal obesity, Visceral fat, Waist-tohip ratio, Waist circumference, Waist-to-height ratio, Swiss adults

\footnotetext{
*Correspondence: murielle.bochud@chuv.ch

${ }^{1}$ Institute of Social and Preventive Medicine (IUMSP), Lausanne University

Hospital (CHUV), Route de la Corniche 10, 1010 Lausanne, Switzerland

Full list of author information is available at the end of the article
}

(c) The Author(s). 2018 Open Access This article is distributed under the terms of the Creative Commons Attribution 4.0 International License (http://creativecommons.org/licenses/by/4.0/), which permits unrestricted use, distribution, and reproduction in any medium, provided you give appropriate credit to the original author(s) and the source, provide a link to the Creative Commons license, and indicate if changes were made. The Creative Commons Public Domain Dedication waiver (http://creativecommons.org/publicdomain/zero/1.0/) applies to the data made available in this article, unless otherwise stated. 


\section{Background}

The impact of breakfast on obesity and cardio-metabolic health is disputed [1-5]. Two distinct aspects need to be considered: 1) breakfast skipping, and 2) type of breakfast in terms of food and nutrient composition. Breakfast also needs to be examined in the context of eating patterns throughout the entire day [6] because its consumption and composition may be related to meals and snacks consumed at other times of the day [7]. Cross-sectional and cohort studies have consistently reported skipping breakfast to be associated with an increased body weight [8-10]. However, experimental evidence is lacking to substantiate these observations [1, $2,11,12]$. Fewer studies have investigated the impact of breakfast composition on cardio-metabolic risk factors [13]. There is growing experimental evidence suggesting that consuming a breakfast rich in protein and fiber is associated with benefits in terms of weight management [2] and cardio-metabolic health [3].

While intervention-based research is instrumental in deciphering causality, most clinical trials are of restricted duration (max. a few months) [2,3], and hence do not assess the long-term impact of selected dietary behaviors on health. In addition, experimental studies often have limited external validity; indeed, their conclusions may not be generalized to the general population. Clearly, further research on whether and how breakfast may influence metabolic health is needed [2-5]. In this context, population-based observational studies provide important complementary evidence because they assess breakfast consumption in real-life settings, in more diverse populations, larger sample sizes, and over longer duration in case of longitudinal design. A few cross-sectional studies investigated the association of breakfast composition with body composition especially abdominal obesity in adult populations [13-17]. Studies in Canada [16] and the United States (U.S.) [14, 15, 17] using nationally representative food consumption data showed that adults taking breakfast made of pre- or un-sweetened ready-to-eat cereals or cooked cereals had lower waist circumference (WC) $[14,15]$ and/or body mass index (BMI) [14-17]. Iqbal et al. [13] showed in both male and female German middle-aged adults that eating salty protein-based breakfast was associated with increased BMI and WC. None of these studies accounted for diet quality during the rest of the day, and most used breakfast skippers as the comparison group. Such comparison is, however, less relevant when investigating the optimal breakfast composition because, as stated previously, most observational studies found that breakfast skippers had increased body weight [7-10].

Switzerland is located in the center of Europe and surrounded by three countries with very different dietary habits: France, Germany and Italy [18-20]. This unique multicultural setting revealed major differences in the consumption of food groups across the three main linguistic regions of the country [21]. In that sense, Switzerland represents an interesting setting to study how various dietary patterns may associate with abdominal obesity. In this study, we explored whether breakfast composition (a posteriori derived dietary patterns) were associated with abdominal obesity in Swiss regular breakfast eaters, using cross-sectional data from the first national nutrition survey, menuCH.

\section{Methods}

We followed the STROBE-nut recommendations for reporting (Additional file 1) [22].

\section{Design and study population}

We analyzed data from the Swiss Nutrition Survey menuCH collected between January 2014 and February 2015 [21]. menuCH is a cross-sectional, nationwide, population-based survey among adults aged 18 to 75 years living in Switzerland [21]. Selection of participants was based on a stratified random sample of the national sampling frame for surveys [23]. Response rate was $38 \%$ : of the 5496 eligible people reachable by phone, 2086 participated in the survey [21]. Participants and non-participants had similar age and marital status, but participants were more frequently women and Swiss nationals [21]. menuCH details are available at: https:// menuch.iumsp.ch.

\section{Dietary assessment}

Food consumption assessment was based on multiple-pass 24-h dietary recalls (24HDR), using the validated software GloboDiet ${ }^{\circ}$, previously known as EPIC-Soft [24, 25]. Dietitians conducted two non-consecutive 24HDR per participant. The first 24HDR was face-to-face and the second by phone, two to six weeks later. Food intake could have been recorded on any day of the week. When possible, dietitians planned interviews with participants on two different weekdays (e.g. not both on Mondays). Special days (e.g. party, holiday, or traveling days) were not excluded from analyses because of high frequency (i.e., about a third of 24HDR). Each food item was then linked with the most appropriate item from an extended research version of the Swiss Food Composition Database [26] (data available for energy, macronutrients, and sodium). For more details on dietary assessment and estimation of misreporting, read [21].

\section{Breakfast definition}

We considered as breakfast all foods and beverages (including water) consumed in the food consumption occasions labeled by participants as 'pre-breakfast (wake-up 
time)' and 'breakfast'. Breakfast was defined as skipped if less than $100 \mathrm{kcal}$ were consumed. This cut-off choice was mainly data driven as shown in Additional file 2, but also based on literature [6]. Survey participants also reported in a questionnaire which day they usually skipped breakfast in a standard week (Monday to Sunday). For further analyses, we took only regular breakfast eaters into consideration, i.e., those breakfasting in both 24HDR and reporting eating breakfast at least 5 days in a standard week. Agreement between 24HDR and questionnaire was good: $93 \%$ of participants who consumed a breakfast in both 24HDR also reported taking a breakfast regularly in the questionnaire.

\section{Food group intake}

Two registered dietitians independently classified foods and beverages into 36 groups of interest according to their nutritional value per typical portion size and their classification in the national food-based dietary guidelines [27] (Additional file 3). We then selected only the 22 food groups whose mean breakfast intake (in g) was at least $5 \%$ of the total daily intake. For example, vegetables were excluded because the mean breakfast intake represented $1 \%$ of the daily intake. We modeled the usual breakfast intake for the selected food groups using Multiple Source Method (MSM, https://nugo.dife.de/ msm) [28-30].

\section{Definition of breakfast composition}

We derived dietary patterns using principal component analysis (PCA, more specifically factor analysis) based on the standardized usual intake for the 22 food groups. In accordance with the scree plot (Additional file 4), we kept three factors. We applied varimax rotation to ease the interpretation. The food groups with a factor loading higher than an absolute value of 0.2 were considered as significant contributors to the pattern. We labelled the dietary patterns based on the food groups positively and negatively correlated to the identified patterns. Each regular breakfast eater was predicted a factor score for each pattern and was then categorized into a tertile (T1, T2, T3). The participants in the third tertile (T3) ate breakfast whose content was the closest to the pattern. The applicability of the data to factor analysis was considered as acceptable based on Kayser-Meyer-Olkin and the Bartlett's sphericity tests (respectively, 0.59 and $P<$ $0.001)[31,32]$.

\section{Outcome assessment}

We assessed abdominal obesity based on waist-to-hip ratio (WHR, $\geq 0.9$ for men, 0.85 for women) [33]. To compare with literature and test whether our findings were dependent on the choice of the anthropometric parameters, we also used WC (i.e., obesity if WC $>90 \mathrm{~cm}$ for men, $84 \mathrm{~cm}$ for women) [33], waist-to-height ratio (WHtR, $\geq 0.5$ ) [34-36], and BMI $\left(\geq 30 \mathrm{~kg} / \mathrm{m}^{2}\right)$ [33]. Dietitians were extensively trained to measure body weight, height, waist and hip circumferences following an international protocol [37]. For waist and hip circumferences, we calculated the mean of the three consecutive measurements taken to the nearest $0.1 \mathrm{~cm}$ using a Gulick I unstretchable tape, equipped with a dynamometer (North Coast Medical, CA, USA).

\section{Covariates}

We calculated total energy and nutrient intake (including alcohol) per recall day, but also at breakfast and during the rest of the day. We computed the mean nutrient intake out of the two days. The intakes of fiber, saturated fat, and sodium during the rest of the day were chosen as proxies for diet quality outside breakfast. We also estimated diet quality outside breakfast creating a nutritional score with six food components, selected from the 2010 Alternate Healthy Heating Index [38]: vegetables, fruit, whole grain, sugar sweetened drinks and fruit juice, nuts and legumes, and red and processed meat. More details about the scoring method and cut-offs are available in the Additional file 5 .

Physical activity was assessed with the short-form International Physical Activity Questionnaire (IPAQ, six questions) [39, 40]. Data were converted into Metabolic Equivalent of Task (MET) minutes per week [41]. Information about education (university degree: yes/no), food literacy (knowing the existence of the Swiss Food Pyramid: yes/no), smoking (never/past/current), nationality (Swiss/non-Swiss), household status (alone/couple with children/couple without children) were assessed by questionnaire. The season was defined according to the date of the first 24HDR when anthropometric measurements were taken (April 15th to October 14th: warm/ October 15th to April 14th: cold). Finally, we considered linguistic regions based on survey participants' home address (German/French/Italian-speaking regions).

\section{Statistical analyses}

We imputed missing data from the six IPAQ questions (between 1 and 16\% of missing value for a single question) to passively calculate MET-min per week using multiple imputations by predictive mean matching through a Markov chain Monte Carlo method. We used multiple regressions accounting for sex, age, physical activity, and height to test the differences between $\mathrm{T} 1$ and T3 in food and nutrient intakes at breakfast and during the rest of the day. To assess the association between breakfast composition and abdominal obesity, we computed multiple logistic regressions using abdominal obesity assessed with WHR (WC, WHtR or BMI, respectively) as the binary outcome variable and the 
tertiles of breakfast type as exposure variables. For sensitivity analyses, we stratified by sex. We also applied multiple linear regression models using $\log -\mathrm{WHR}$ as the outcome variable. The statistical significance of the differences in odds ratios between the three tertiles of each breakfast type was assessed using a Wald test. In addition, we estimated a $P$-value for trend based on a model considering the tertiles as a continuous exposure variable. We carried out all statistical analyses using STATA version 14 (Stata Corp., College Station, TX, USA).

\section{Results}

Of the 2086 original survey participants [21], we excluded 67 of them (3\%): 34 for missing waist and hip circumference measurements (i.e., 27 for pregnancy or lactation, 6 for handicap and 1 for refusal), 29 for missing second $24 \mathrm{HDR}, 4$ for incomplete questionnaire on sociodemographic data and usual breakfast skipping days. Table 1 summarizes the characteristics of the included 2019 survey participants (46\% of men). About one quarter of the survey sample presented a WHR above current recommendations and 13\% were obese according to BMI measurement.

Sixty-seven per cent of survey participants $(N=1351)$ were regular breakfast eaters. Their mean daily energy intake, estimated out of two 24HDR, was $2217 \mathrm{kcal}$, respectively $2574 \mathrm{kcal}$ for men and 1953 for women (Table $1)$. Mean $( \pm \mathrm{SD})$ breakfast energy intake was $479 \mathrm{kcal}( \pm$ 232), i.e., 554 and $424 \mathrm{kcal}$ for men and women, respectively. The proportions of regular breakfast eaters with a WHR above the recommended cut-off were 26\%; 45 and $12 \%$ in men and women, respectively.

After adjustment for sex, age, physical activity, total energy intake, education, food literacy, smoking, nationality, household status, season, and linguistic region, the odds of having an increased WHR were 1.6 times larger for occasional than for regular breakfast eaters (OR 1.59, 95\% CI: 1.21 to 2.08 , Additional file 6).

From PCA, three main dietary patterns emerged among the 1351 regular breakfast eaters (Fig. 1): 1) 'traditional' breakfast, rich in refined bread and bread products, butter and sweet spread (e.g. jam, honey), 2) 'prudent' breakfast, made of fruit, unprocessed and unsweetened cereal flakes, nuts/seeds and yogurt, which are typical ingredients of the Swiss recipe of 'Birchermuesli', and 3) 'western' breakfast, rich in processed and pre-sweetened breakfast cereals, milk, sugar confectionary and sugary soft drinks, including fruit nectars made of fruit juice, sugar and water. The cumulative percentage of explained variance was 26\% (Additional file 4).

Table 1 shows that people adhering the most to the 'traditional' breakfast were rather older men with increased abdominal fat. Older and more educated people preferred the 'prudent' breakfast while younger men favored the 'western' breakfast. More details about participants' characteristics by breakfast type can be found in Additional file 7.

Additional file 8 describes the nutrient intakes at breakfast by breakfast type. Succinctly, the 'traditional' breakfast was the richest in saturated fat and sodium. The 'prudent' breakfast had the highest fiber content. The median fiber intake among participants in T3 was more than doubled compared to those in T1 $(6.7 \mathrm{~g}$ vs $2.8 \mathrm{~g},+3.9 \mathrm{~g})$. After adjustment for sex, age, physical activity, and measured height, this difference was reduced to $+0.2 \mathrm{~g}$ (Additional file 8$)$ but remains significant $(P<$ 0.001). Additional files 9 and 10 show the differences in nutrient and food intakes between T1 and T3 for the rest of the day. In brief, for the 'prudent' breakfast, people classified in T3 scored significantly higher in the six-food-component nutritional score (+3\%) compared to people in T1. For the 'western' breakfast, sugars intake were higher in people classified in T3 than those in $\mathrm{T} 1$. The former (T3) scored $4 \%$ below the latter (T1) in the six-food-component nutritional score.

After full adjustment for potential confounding factors, including diet quality for the rest of the day, the 'traditional' and 'western' breakfasts were not associated with elevated WHR (OR 1.00 for T3 vs. T1, 95\% CI: 0.67 to 1.50 , and OR $1.16,95 \%$ CI: 0.79 to 1.71 , respectively, Table 2). The 'prudent' breakfast was negatively associated with abdominal obesity. Participants with highest factor score (T3) for the 'prudent' pattern were less likely to have abdominal obesity than those with lowest factor score (T1). After adjustment for diet quality during the rest of the day (Model 4), the association became weaker and non-significant (T3 vs. T1: OR 0.72, 95\% CI: 0.47 to 1.08 , $P$ for trend $=0.10)$. When WHR was analyzed continuously, a shift from T1 to T3 was associated with a significant difference of -0.012 in log-WHR (Additional file 11). This corresponds to $1.2 \%$ lower WHR ( $95 \% \mathrm{CI},-0.2 \%$ to $-2.2 \%)$. In sensitivity analyses, stratification by sex did not influence the results: odds ratios remained similar in both sexes for all three patterns (data not shown).

Figure 2 compares the odds ratios between the 'prudent' breakfast and abdominal obesity assessed with the three other parameters (i.e., WC, WHtR or BMI) using the fully adjusted models (see Additional file 12 for the 'traditional' and 'western' patterns). We observed a significant negative association between the 'prudent' breakfast and BMI (OR 0.51, 95\% CI: 0.31 to 0.85). When considering elevated WC and WHtR as outcomes, the associations were in the same direction although the CIs contained the null value.

\section{Discussion}

We found out that consuming a 'prudent' breakfast composed of fruit, unprocessed and unsweetened cereal 
Table 1 Description of survey participants, by breakfasting regularity, and by breakfast type (by tertile in regular breakfast eaters)

\begin{tabular}{|c|c|c|c|c|c|c|c|c|c|c|c|c|c|c|c|}
\hline \multirow[t]{2}{*}{ Characteristics } & \multirow{2}{*}{\multicolumn{2}{|c|}{$\begin{array}{l}\text { All survey } \\
\text { participants }\end{array}$}} & \multirow{2}{*}{\multicolumn{2}{|c|}{$\begin{array}{l}\text { Occasional } \\
\text { breakfast } \\
\text { eaters }\end{array}$}} & \multirow{2}{*}{\multicolumn{2}{|c|}{$\begin{array}{l}\text { Regular } \\
\text { breakfast } \\
\text { eaters }\end{array}$}} & \multicolumn{3}{|c|}{$\begin{array}{l}\text { Traditional' - } \\
\text { Pattern } 1\end{array}$} & \multicolumn{3}{|c|}{$\begin{array}{l}\text { 'Prudent' - } \\
\text { Pattern } 2\end{array}$} & \multicolumn{3}{|c|}{$\begin{array}{l}\text { 'Western' - } \\
\text { Pattern } 3\end{array}$} \\
\hline & & & & & & & $\mathrm{T} 1^{f}$ & $\mathrm{~T} 2$ & T3 & $\mathrm{T} 1$ & $\mathrm{~T} 2$ & T3 & $\mathrm{T1}$ & $\mathrm{T} 2$ & T3 \\
\hline$N$ of participants & $\begin{array}{l}2019 \\
(100 \%\end{array}$ & & 668 & 33\%) & 1351 & (67\%) & 451 & 450 & 450 & 451 & 450 & 450 & 451 & 450 & 450 \\
\hline \multicolumn{16}{|c|}{ Sex, $n(\%)$} \\
\hline Male & 926 & 46 & 353 & 53 & 573 & 42 & 37 & 38 & 53 & 43 & 44 & 40 & 37 & 43 & 47 \\
\hline Female & 1093 & 54 & 315 & 47 & 778 & 58 & 63 & 62 & 47 & 57 & 56 & 60 & 63 & 57 & 53 \\
\hline \multicolumn{16}{|c|}{ Age, $n(\%)$} \\
\hline 18-34 years old & 541 & 27 & 238 & 36 & 303 & 22 & 28 & 23 & 17 & 32 & 18 & 18 & 20 & 17 & 30 \\
\hline 35-49 years old & 588 & 29 & 205 & 31 & 383 & 28 & 30 & 29 & 26 & 31 & 27 & 27 & 26 & 29 & 29 \\
\hline 50-64 years old & 554 & 27 & 167 & 25 & 387 & 29 & 29 & 28 & 29 & 23 & 32 & 31 & 31 & 30 & 25 \\
\hline 65-75 years old & 336 & 17 & 58 & 9 & 278 & 21 & 13 & 20 & 29 & 14 & 24 & 24 & 22 & 23 & 16 \\
\hline
\end{tabular}

Education: Highest degree, $n$ (\%)

Secondary (e.g. apprenticeship and below)

Tertiary (e.g. high technical school, university)

Mean of two 24-h dietary recalls (in $\mathrm{kcal}$ )

Mean of two 24-h dietary recalls (in kcal)

MET-min per week (from IPAQ)

Waist-to-hip ratio: $\geq 0.9\left({ }^{3}\right) ; \geq 0.85(q)^{\mathrm{b}, \mathrm{c}}$

Waist circumference: $>90 \mathrm{~cm}\left({ }^{\lambda}\right) ;>84 \mathrm{~cm}$ $(q)^{b}$

Waist-to-height ratio: $\geq 0.5(\hat{\partial}, \text { of })^{d}$

Body mass index: $\geq 30 \mathrm{~kg} / \mathrm{m}^{2}(\hat{0}, q)^{b}$

$\begin{array}{lllllllllllllll}1042 & 52 & 363 & 54 & 679 & 50 & 48 & 49 & 54 & 52 & 53 & 45 & 49 & 54 & 48 \\ 977 & 48 & 305 & 46 & 672 & 50 & 52 & 51 & 46 & 48 & 47 & 55 & 51 & 46 & 52\end{array}$

Total energy intake, mean $( \pm S D)^{a}$

$\begin{array}{lllllllllllllll}2175 & 710 & 2092 & 740 & 2217 & 690 & 2110 & 2074 & 2467 & 2182 & 2243 & 2225 & 2106 & 2171 & 2373\end{array}$

Breakfast energy intake, mean $( \pm S D)$

$\begin{array}{lllllllllllllll}381 & 261 & 181 & 192 & 479 & 232 & 386 & 412 & 639 & 420 & 499 & 519 & 451 & 440 & 546\end{array}$

Self-reported physical activity, mean ( \pm SD)

$\begin{array}{lllllllllllllll}3761 & 3287 & 3816 & 3404 & 3730 & 3220 & 3580 & 3547 & 3974 & 3473 & 3960 & 3665 & 3751 & 3680 & 3654\end{array}$

Abdominal obesity assessment, $n$ (\%)

$\begin{array}{lllllllllllllll}546 & 27 & 191 & 29 & 355 & 26 & 21 & 27 & 31 & 24 & 32 & 24 & 25 & 29 & 25 \\ 701 & 35 & 237 & 35 & 464 & 34 & 30 & 35 & 38 & 30 & 42 & 31 & 36 & 37 & 30 \\ 799 & 40 & 285 & 43 & 514 & 38 & 32 & 39 & 43 & 35 & 46 & 34 & 38 & 42 & 34 \\ 255 & 13 & 114 & 17 & 141 & 10 & 9 & 11 & 11 & 12 & 12 & 7 & 10 & 10 & 11\end{array}$

${ }^{a}$ Mean daily energy intake was 2511 and $1891 \mathrm{kcal}$ among all male and female survey participants, and 2574 and $1953 \mathrm{kcal}$ among male and female regular breakfast eaters, respectively

${ }^{b}$ Cut-offs from the World Health Organization [33]

${ }^{c}$ The proportions of men and women above the cut-off for waist-to-hip ratio was 44 and $13 \%$ among all survey participants, and 45 and $12 \%$ among regular breakfast eaters, respectively

${ }^{d}$ Cut-off suggested by Schneider [34], Browning [35] and Ashwell [36] et al.

${ }^{e}$ Regular breakfast eaters were defined as survey participants who took a breakfast of at least $100 \mathrm{kcal}$ in both of their 24-h dietary recalls and reported eating breakfast at least 5 days in a usual week

Breakfast energy intake was 554 and $424 \mathrm{kcal}$ among male and female regular breakfast eaters, respectively

fIn this second part of the table, only proportions, respectively, means for continuous variables, are presented in the 1351 regular breakfast eaters

flakes, nuts/seeds and yogurt (typical Swiss recipe of 'Birchermuesli') was associated with less abdominal obesity in Swiss regular breakfast eaters. The association was partly due to higher overall diet quality in these people. Our finding is in line with results from a recent meta-analysis of 13 observational studies regarding overall dietary patterns also derived by PCA [42]. The highest category of 'healthy/prudent' pattern (with high-factor loadings in fruits, vegetables, and whole grain) was associated with reduced risk of central obesity compared with the lowest category (pooled OR 0.81, 95\% CI: 0.66 to 0.96 , $\left.\mathrm{I}^{2}=69.8\right)[42]$.

\section{High-fiber breakfast}

In our research, all three breakfast types derived by PCA were rich in carbohydrates. Only the 'prudent' pattern 


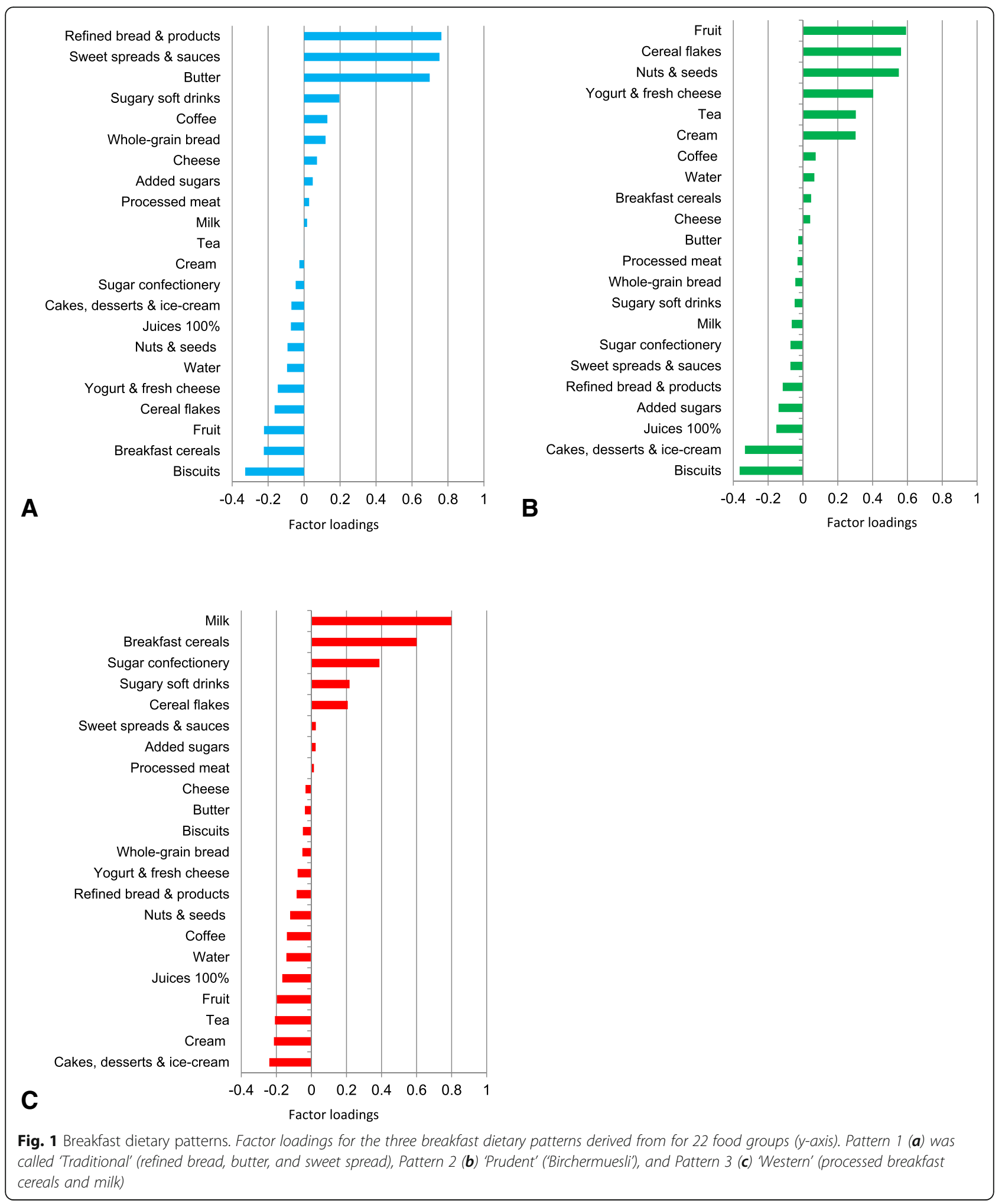

'Birchermuesli' had the particularity to be also rich in fiber coming from whole grain cereals, fruit and nuts/ seeds, even though the higher fiber intake in T3 was partly confounded by differences in sex, age, physical activity, and height of the people in T3 compared to people in T1 (Additional file 8). The few randomized controlled trials that tested the effect of breakfast composition on cardio-metabolic health have also suggested 
Table 2 Association between breakfast type and abdominal obesity (WHR $\geq 0.9($ đ) $; \geq 0.85($ q),$N=1351)$

\begin{tabular}{|c|c|c|c|c|c|c|c|c|}
\hline & \multicolumn{8}{|c|}{ Breakfast composition } \\
\hline & \multirow{2}{*}{$\begin{array}{l}\mathrm{T} 1 \\
\mathrm{OR}\end{array}$} & \multicolumn{3}{|l|}{$\mathrm{T} 2$} & \multicolumn{3}{|l|}{ T3 } & \multirow[b]{2}{*}{$\begin{array}{l}P \text {-Value for trend } \\
{ }_{2}\end{array}$} \\
\hline & & OR & $95 \%$ & & OR & $95 \% \mathrm{C}$ & & \\
\hline \multicolumn{9}{|l|}{ 'Traditional' - Refined bread, butter and sweet spread } \\
\hline Crude & $\begin{array}{l}1 \\
\text { (ref) }\end{array}$ & 1.40 & 1.03 & 1.90 & 1.72 & 1.27 & 2.32 & $<0.001^{* *}$ \\
\hline $\begin{array}{l}\text { Model } 1 \\
\text { (sex }+ \text { age })\end{array}$ & $\begin{array}{l}1 \\
\text { (ref) }\end{array}$ & 1.25 & 0.87 & 1.80 & 0.89 & 0.61 & 1.28 & 0.45 \\
\hline $\begin{array}{l}\text { Model } 2 \\
(\text { sex }+ \text { age + physical activity + total energy intake })^{\prime}\end{array}$ & $\begin{array}{l}1 \\
\text { (ref) }\end{array}$ & 1.31 & 0.91 & 1.90 & 0.93 & 0.64 & 1.36 & 0.67 \\
\hline $\begin{array}{l}\text { Model } 3 \\
\text { (11 covariates) }^{1}\end{array}$ & $\begin{array}{l}1 \\
\text { (ref) }\end{array}$ & 1.39 & 0.95 & 2.03 & 1.00 & 0.68 & 1.48 & 0.95 \\
\hline $\begin{array}{l}\text { Model } 4 \\
\text { (16 covariates, including diet quality during the rest of the day - nutrient }+ \text { food-based } \\
\text { approach) }\end{array}$ & $\begin{array}{l}1 \\
\text { (ref) }\end{array}$ & 1.32 & 0.90 & 1.93 & 1.00 & 0.67 & 1.50 & 0.99 \\
\hline \multicolumn{9}{|l|}{ 'Prudent' - Fruit, unprocessed and unsweetened cereal flakes, nuts/seeds and yogurt } \\
\hline Crude & $\begin{array}{l}1 \\
\text { (ref) }\end{array}$ & 1.48 & 1.10 & 1.99 & 0.99 & 0.73 & 1.35 & 0.96 \\
\hline $\begin{array}{l}\text { Model } 1 \\
(\text { sex }+ \text { age })\end{array}$ & $\begin{array}{l}1 \\
\text { (ref) }\end{array}$ & 0.98 & 0.68 & 1.40 & 0.60 & 0.41 & 0.87 & $0.006^{*}$ \\
\hline $\begin{array}{l}\text { Model } 2 \\
(\text { sex }+ \text { age }+ \text { physical activity }+ \text { total energy intake })^{7}\end{array}$ & $\begin{array}{l}1 \\
\text { (ref) }\end{array}$ & 1.00 & 0.70 & 1.44 & 0.59 & 0.40 & 0.86 & $0.005^{*}$ \\
\hline $\begin{array}{l}\text { Model } 3 \\
\text { (11 covariates) }^{1}\end{array}$ & $\begin{array}{l}1 \\
\text { (ref) }\end{array}$ & 1.01 & 0.70 & 1.47 & 0.60 & 0.41 & 0.90 & $0.011^{*}$ \\
\hline $\begin{array}{l}\text { Model } 4 \\
\text { (16 covariates, including diet quality during the rest of the day }- \text { nutrient }+ \text { food-based } \\
\text { approach) }\end{array}$ & $\begin{array}{l}1 \\
\text { (ref) }\end{array}$ & 1.09 & 0.74 & 1.59 & 0.72 & 0.47 & 1.08 & 0.10 \\
\hline \multicolumn{9}{|l|}{ 'Western' - Processed breakfast cereals and milk } \\
\hline Crude & $\begin{array}{l}1 \\
\text { (ref) }\end{array}$ & 1.24 & 0.93 & 1.67 & 1.00 & 0.74 & 1.36 & 0.98 \\
\hline $\begin{array}{l}\text { Model } 1 \\
(\text { sex }+ \text { age })\end{array}$ & $\begin{array}{l}1 \\
\text { (ref) }\end{array}$ & 1.12 & 0.79 & 1.58 & 1.07 & 0.74 & 1.53 & 0.71 \\
\hline $\begin{array}{l}\text { Model } 2 \\
(\text { sex }+ \text { age }+ \text { physical activity }+ \text { total energy intake })^{\prime}\end{array}$ & $\begin{array}{l}1 \\
\text { (ref) }\end{array}$ & 1.14 & 0.80 & 1.62 & 1.09 & 0.75 & 1.57 & 0.63 \\
\hline $\begin{array}{l}\text { Model } 3 \\
\text { (11 covariates) }^{1}\end{array}$ & $\begin{array}{l}1 \\
\text { (ref) }\end{array}$ & 1.18 & 0.83 & 1.70 & 1.21 & 0.83 & 1.77 & 0.32 \\
\hline $\begin{array}{l}\text { Model } 4 \\
(16 \text { covariates, including diet quality during the rest of the day }- \text { nutrient }+ \text { food-based } \\
\text { approach })^{2}\end{array}$ & $\begin{array}{l}1 \\
\text { (ref) }\end{array}$ & 1.10 & 0.76 & 1.58 & 1.16 & 0.79 & 1.71 & 0.45 \\
\hline \multicolumn{9}{|c|}{ 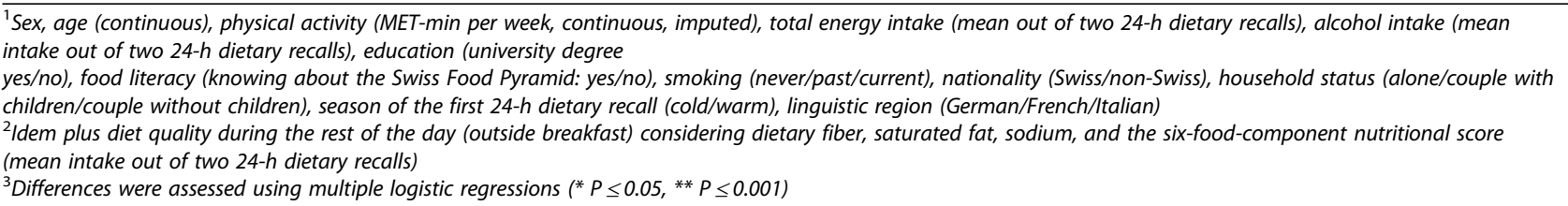 } \\
\hline
\end{tabular}

that eating a high fiber breakfast might be the most protective strategy [2, 3]. Among those trials, one is particularly interesting for its relative long-term intervention. Adamsson et al. [43] demonstrated in 79 regular breakfast eaters that a normocaloric whole-grain cereal-based breakfast, which was very similar to our 'prudent' pattern, could reduce the sagittal abdominal diameter by $0.6 \mathrm{~cm}(P=0.034)$. The authors also showed a reduction in circulating plasma inflammation markers within the three-month intervention. In our findings, Swiss regulars breakfast eaters taking a 'prudent' breakfast (in T3) had 1.2\% lower WHR compared to those taking a breakfast distant from this pattern (in T1) (Additional file 11). Given the mean WHR at 0.829 in our sample and supposing the mean hip circumference staying 


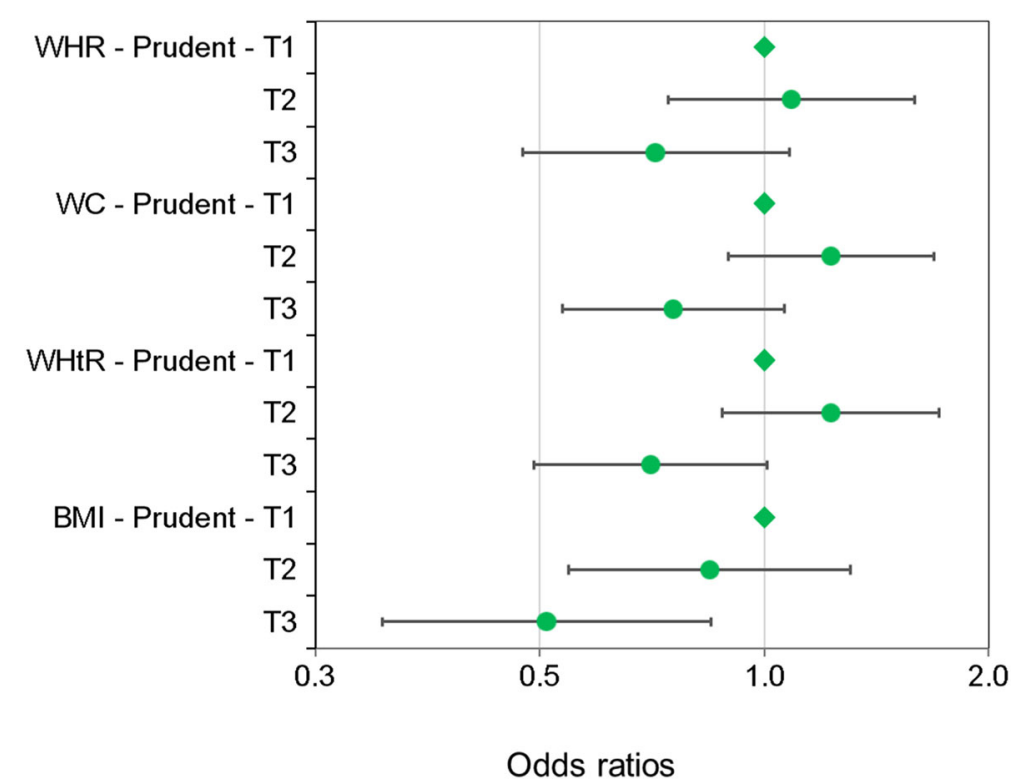

Fig. 2 Association between the 'prudent' breakfast and four obesity anthropometric parameters. Odds ratios between the 'prudent' breakfast (tertiles 1 to 3: T3 being closely associated with the pattern) and abdominal obesity (waist-to-hip ratio (WHR): $\geq 0.9$ (O)); $\geq 0.85$ (Q)); waist

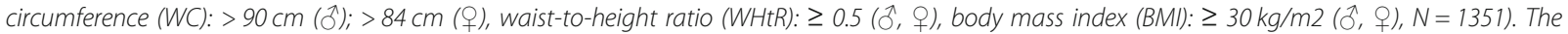
logistic models were adjusted for sex, age, physical activity, total energy intake, alcohol intake, education, food literacy, smoking, nationality, household status, season of the first 24-h dietary recall, linguistic region, diet quality during the rest of the day (outside breakfast)

constant at $100.1 \mathrm{~cm}$, this would correspond to a mean difference of $-1 \mathrm{~cm}$ in WC.

The biological mechanisms behind the potential protective effect of consuming a breakfast rich in viscous and cereal fibers could be multiple. On the one hand, low-glycemic index carbohydrates, such as those in whole grain cereals, could lessen postprandial glucose response, limiting thus insulin production [3, 44-46]. On the other hand, dietary fiber may lower the release of free fatty acids from adipose tissues that cause insulin resistance. In turn, the diminution of insulin resistance reduces the production of pro-inflammatory mediators, and in fine, abdominal fat [3, 44, 47, 48]. Mediation mechanisms through the microbiota are likely to exist, stressing again the importance of dietary fiber for cardio-metabolic health [48].

\section{Breakfast composition in other population-based studies}

Contrary to previous publications in North America, we did not detect an association between eating breakfast cereals (i.e., 'western' pattern) and abdominal obesity. In the U.S. National Health and Nutrition Examination Survey (NHANES) 1988-1994, eating ready-to-eat or cooked cereals, or quick breads was associated with significantly lower BMI compared to skipping breakfast or eating meats and/or eggs for breakfast [17]. Similarly, in young adults aged 20-39years from the NHANES 1999-2006, breakfast including ready-to-eat cereals was associated with an improved cardio-metabolic risk profile [14]. O'Neil et al. also found in older adults that breakfasts composed of grains, pre- or un-sweetened ready-to-eat or cooked cereals, low-fat milk, and fruit were associated with lower BMI and WC than breakfast skipping [15]. The 2004 Canadian Community Health Survey also showed that mean BMI was significantly lower among consumers of ready-to-eat cereals at breakfast [16]. The fact that their comparison groups were breakfast skippers [15, 16], heterogeneous groups of 'other breakfast' consumers [14, 16], and/or groups with dietary patterns providing variable energy and nutrient intakes [15, 17] may explain the apparent inconsistency between North American and Swiss findings.

The other European study (in Germany) using PCA to derive breakfast composition from three 24HDR [13] found that the breakfast made of milk and breakfast cereals (undefined in terms of nutrient content) was not associated with increased or decreased WC, nor BMI. This 'dairy \& breakfast cereal pattern' was, however, associated with a better multi-biomarker cardio-metabolic profile in men. The same article highlighted that the 'processed food pattern', composed of processed meat, cheese, vegetables, margarine, eggs, and bread, was positively associated with WC and BMI in both sexes. In Switzerland, a comparison between a high-fiber carbohydrate-based breakfast such as 'Birchermuesli' and a protein-based breakfast would have been interesting, since some evidence suggests that eating a protein-based breakfast may have beneficial effects too $[2,3]$. 
Nevertheless, no protein-based breakfast emerged from the PCA as a main pattern, probably because this type of breakfast is less common than in Germany. Of note, the North American and German studies did not adjust for diet quality during the rest of the day.

While types of foods and beverages usually consumed at breakfast vary across countries, variations also exist in the contribution of breakfast to the daily energy intake. In our survey, breakfast brought $22 \%$ of total energy intake among regular breakfast eaters, and $18 \%$ among all survey participants, including occasional breakfast eaters. This proportion is slightly higher than in other western high-income countries: e.g., $14 \%$ in the Netherlands [49], $15 \%$ in Britain [50], $15 \%$ in the U.S. [15], 17\% in France [51], or 16\% in Spain [52]. This may represent different eating habits in the distribution of daily food consumption occasions, the proportion of breakfast skippers, and/or the definition of breakfast. Although breakfast accounts only for less than one fifth of the total energy intake across countries, understanding the impact of breakfast composition on health could complement the overall diet approach. This can also help define meal-based recommendations to assist populations in achieving the recommended daily intake $[6$, 53].

\section{Strengths and limitations}

The present study has several strengths. First, we used data from a large, relatively representative sample of the Swiss population. Second, we focused on regular breakfast eaters to avoid comparison with breakfast skippers, who are known to have higher obesity prevalence in observational studies [1, 8-10] (Additional file 6). Third, specifically trained dietitians conducted the 24HDR using the internationally validated software GloboDiet ${ }^{\circ}$. In addition, we assessed the quality of $24 \mathrm{HDR}$ via several quality control procedures and underreporting was limited $[21,54]$. Fourth, the same dietitian were also intensely trained to measure waist and hip circumferences. We tested inter-dietitian reproducibility during training sessions and organized two retraining sessions during the year of data collection. Intra-dietitian reproducibility was very high (Pearson's correlation coefficients: $r \geq 0.99$, data not shown). Fifth, we derived breakfast composition pattern based on the usual food intake modeled by MSM instead of using only the mean of two days. Sixth, we adjusted for most known confounders, including diet quality during the rest of the day. Seventh, our conclusions were independent of the choice of the anthropometric parameters we used as proxies of abdominal obesity.

The main limitation is the cross-sectional design. Thus, it is difficult to ascertain the temporal order of exposure and disease, essential for causal inference.
Namely, people may have changed their diet for weight management. In addition, residual confounding may have biased the associations found between breakfast composition and abdominal obesity. Our results, however, open new hypotheses regarding the best choice for breakfast and complement the limited evidence from randomized controlled trials. An additional limitation is related to the method of PCA, which makes the comparison between groups/tertiles unintuitive. Indeed, breakfast eaters were not classified based on fixed food intake cut-offs, but their closeness or distance to a pattern. In other words, it is hard to picture the breakfast of people in the reference group (T1). Additionally, the three main identified dietary patterns explained only $26 \%$ of total variance. This indicates that breakfast patterns were complex and multiple in Switzerland. Thus, focusing only on three patterns explaining most variance reduces complexity but is imperfect. In our study, $27 \%$ of regular breakfast consumers were classified into none of the three T3 (Additional file 13), and $24 \%$ into more than one T3. These people respectively took other types of breakfast or foods overlapping several of the three selected patterns. We may also assume that some participants took one type of breakfast on the first recall day and another type on the second day. Currently, we know little about within-person variability in breakfast choice. In the U.S., Kant and Graubard showed that $17 \%$ of adults in NHANES 2005-2010 reported taking a breakfast in only one of the two 24HDR [55], and Sieger et al. [56] reported higher energy intake variability for snack and breakfast than for lunch and dinner. However, these references inform only about the variability in energy intake and not in food choices, which may be more limited at breakfast than for other meals, especially among regular breakfast eaters. Novel data mining techniques (e.g. maching learning algorithms) may help in defining more precisely the usual type of consumed meals $[57,58]$. Furthermore, the inconsistent definitions of breakfast and breakfast skipping across studies and countries $[6,59]$ renders comparisons difficult. Finally, the method of 24HDR is sensitive to social desirability and recall bias, which may be important sources of under- or over-reporting in terms of food intake [60].

\section{Conclusions}

Our study shows that a 'prudent' breakfast, based on fruit, unprocessed and unsweetened cereal flakes, nuts/ seeds and yogurt, was associated with reduced abdominal obesity. This association was partly explained by a healthier diet during the rest of the day. Our findings need confirmation in other settings, such as in longitudinal studies, and, preferably, in long-term randomized controlled trials in free-living subjects. 


\section{Additional files}

Additional file 1: Completed STROBE-nut checklist. (DOCX 25 kb)

Additional file 2: Histogram of the variable energy intake consumed at breakfast per recall day using defined intervals of $50 \mathrm{kcal}$. (DOCX $17 \mathrm{~kb}$ )

Additional file 3: Description of foods and beverages included in the food groups used to derive dietary patterns. (DOCX 29 kb)

Additional file 4: Scree plot of eigenvalues and number of factors. (DOCX $16 \mathrm{~kb}$ )

Additional file 5: Calculation of the nutritional score used to assess food-based diet quality for the rest of the day. (DOCX $19 \mathrm{~kb}$ )

Additional file 6: Association between breakfast skipping and WHR. (DOCX $19 \mathrm{~kb}$ )

Additional file 7: Associations between covariates and breakfast composition patterns. (DOCX $22 \mathrm{~kb}$ )

Additional file 8: Assessment of differences in nutrient intakes at breakfast by breakfast type. (DOCX $25 \mathrm{~kb}$ )

Additional file 9: Assessment of differences in nutrient intakes for the rest of the day by breakfast type. (DOCX $25 \mathrm{~kb}$ )

Additional file 10: Assessment of differences in food intakes for the rest of the day by breakfast ype. (DOCX $25 \mathrm{~kb}$ )

Additional file 11: Association between breakfast type and WHR (continuous). (DOCX $21 \mathrm{~kb}$ )

Additional file 12: Association between the 'prudent' breakfast and four obesity anthropometric parameters. (DOCX 104 kb)

Additional file 13: Distribution of regular breakfast eaters in the three breakfast types. (DOCX $20 \mathrm{~kb}$ )

\section{Abbreviations}

24HDR: 24-Hour Dietary Recalls; BMI: Body Mass Index; IPAQ: International Physical Activity Questionnaire; menuCH: First Swiss Nutrition Survey MET: Metabolic Equivalent of Task; MSM: Multiple Source Method: NHANES: National Health and Nutrition Examination Survey; PCA: Principal Component Analysis; T: Tertile; U.S.: United States; WC: Waist Circumference; WHR: Waist-to-Hip ratio; WHtR: Waist-to-Height Ratio

\section{Acknowledgements}

The authors thank all the participants at the menuCH survey as well as the collaborators who made it possible.

\section{Funding}

This research is funded by the Swiss Food Safety and Veterinary Office (project ARAMIS 5.16.01). The survey funders were involved in the survey design and the writing of the manuscript. The survey funders had no direct role in the collection, analyses, interpretation of data, nor the decision to publish the results.

\section{Availability of data and materials}

The whole dataset (raw data) as well as relevant documents (e.g. questionnaires, codebook) are accessible for research institutions in the open data repository for project-related research: https://menuch.iumsp.ch.

\section{Authors' contributions}

$A C, K C$ and $M B$ conceived the manuscript. AC defined the methodology, analyzed the data and drafted the manuscript. JP advised for the data analyses. $C A$ and $A Z$ were involved in literature review and primary data analyses. ECF and CAZ reviewed and complemented the parts of the manuscript about the Swiss version of GloboDiet ${ }^{\oplus}$ and linkage of the food consumption data with the Swiss Food Composition Database. All co-authors reviewed the manuscript and provided critical recommendations, and approved the final manuscript.

\section{Ethics approval and consent to participate}

This survey was conducted according to the guidelines laid down in the Declaration of Helsinki and all procedures were approved by the corresponding regional ethics committees (lead committee in Lausanne, Protocol 26/13, approved on 12 February 2013). Written informed consent was obtained from all participants.
Consent for publication

Not applicable.

\section{Competing interests}

The authors declare that they have no competing interests.

\section{Publisher's Note}

Springer Nature remains neutral with regard to jurisdictional claims in published maps and institutional affiliations.

\section{Author details}

${ }^{1}$ Institute of Social and Preventive Medicine (IUMSP), Lausanne University Hospital (CHUV), Route de la Corniche 10, 1010 Lausanne, Switzerland. 'Ecole de Santé Publique, Centre de Recherche en Epidémiologie, Biostatistique et Recherche Clinique, Université libre de Bruxelles, Route de Lennik 808, 1070 Bruxelles, Belgium. ${ }^{3}$ Risk Assessment Division, Nutrimonitoring Sector, Federal Food Safety and Veterinary Office (FSVO), Schwarzenburgstrasse 155, 3003 Bern, Switzerland.

Received: 12 June 2018 Accepted: 11 November 2018 Published online: 20 November 2018

\section{References}

1. Brown AW, Bohan Brown MM, Allison DB. Belief beyond the evidence: using the proposed effect of breakfast on obesity to show 2 practices that distort scientific evidence. Am J Clin Nutr. 2013:98(5):1298-308.

2. Leidy $\mathrm{HJ}$, et al. Evaluating the intervention-based evidence surrounding the causal role of breakfast on markers of weight management, with specific focus on breakfast composition and size. Adv Nutr. 2016;7(3):563S-75S.

3. Maki KC, Phillips-Eakley AK, Smith KN. The effects of breakfast consumption and composition on metabolic wellness with a focus on carbohydrate metabolism. Adv Nutr. 2016;7(3):613S-21S

4. Rosato $\mathrm{V}$, et al. Energy contribution and nutrient composition of breakfast and their relations to overweight in free-living individuals: a systematic review. Adv Nutr. 2016:7(3):455-65.

5. Quatela A, et al. The Energy Content and Composition of Meals Consumed after an Overnight Fast and Their Effects on Diet Induced Thermogenesis: A Systematic Review, Meta-Analyses and Meta-Regressions. Nutrients. 2016;8(11).

6. Leech RM, et al. Understanding meal patterns: definitions, methodology and impact on nutrient intake and diet quality. Nutr Res Rev. 2015;28(1):1-21.

7. St-Onge MP, et al. Meal timing and frequency: implications for cardiovascular disease prevention: a scientific statement from the American Heart Association. Circulation. 2017;135(9):e96-e121.

8. Mesas $A E$, et al. Selected eating behaviours and excess body weight: a systematic review. Obes Rev. 2012;13(2):106-35.

9. Horikawa C, et al. Skipping breakfast and prevalence of overweight and obesity in Asian and Pacific regions: a meta-analysis. Prev Med. 2011;53(4-5):260-7.

10. Szajewska $H$, Ruszczynski M. Systematic review demonstrating that breakfast consumption influences body weight outcomes in children and adolescents in Europe. Crit Rev Food Sci Nutr. 2010:50(2):113-9.

11. Chowdhury EA, et al. The causal role of breakfast in energy balance and health: a randomized controlled trial in obese adults. Am J Clin Nutr. 2016; 103(3):747-56.

12. Geliebter A, et al. Skipping breakfast leads to weight loss but also elevated cholesterol compared with consuming daily breakfasts of oat porridge or frosted cornflakes in overweight individuals: a randomised controlled trial. J Nutr Sci. 2014:3:e56.

13. Iqbal K, et al. Breakfast quality and cardiometabolic risk profiles in an upper middle-aged german population. Eur J Clin Nutr. 2017:71(11):1312-20.

14. Deshmukh-Taskar $P$, et al. The relationship of breakfast skipping and type of breakfast consumed with overweight/obesity, abdominal obesity, other cardiometabolic risk factors and the metabolic syndrome in young adults. The National Health and Nutrition Examination Survey (NHANES): 19992006. Public Health Nutr. 2013:16(11):2073-82.

15. O'Neil CE, Nicklas TA, Fulgoni VL 3rd. Nutrient intake, diet quality, and weight/adiposity parameters in breakfast patterns compared with no breakfast in adults: National Health and nutrition examination survey 20012008. J Acad Nutr Diet. 2014;114(12 Suppl):S27-43.

16. Barr SI, DiFrancesco L, Fulgoni VL 3rd. Association of breakfast consumption with body mass index and prevalence of overweight/obesity in a nationallyrepresentative survey of Canadian adults. Nutr J. 2016;15:33. 
17. Cho $\mathrm{S}$, et al. The effect of breakfast type on total daily energy intake and body mass index: results from the third National Health and nutrition examination survey (NHANES III). J Am Coll Nutr. 2003;22(4):296-302.

18. Slimani N, et al. Diversity of dietary patterns observed in the European prospective investigation into Cancer and nutrition (EPIC) project. Public Health Nutr. 2002;5(6B):1311-28.

19. Freisling $H$, et al. Region-specific nutrient intake patterns exhibit a geographical gradient within and between European countries. J Nutr. 2010;140(7):1280-6.

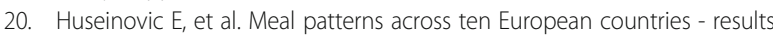
from the European prospective investigation into Cancer and nutrition (EPIC) calibration study. Public Health Nutr. 2016;19(15):2769-80.

21. Chatelan A, et al. Major Differences in Diet across Three Linguistic Regions of Switzerland: Results from the First National Nutrition Survey menuCH. Nutrients. 2017;9(11). https://doi.org/10.3390/nu9111163.

22. Lachat $\mathrm{C}$, et al. Strengthening the reporting of observational studies in epidemiology-nutritional epidemiology (STROBE-nut): an extension of the STROBE statement. PLoS Med. 2016;13(6):e1002036

23. Federal Statistical Office. Stichprobenrahmen für Personen- und Haushaltserhebungen (Swiss persons and households registry). 2018. https:// www.bfs.admin.ch/bfs/de/home/grundlagen/volkszaehlung/volkszaehlung-teilgesamtsystem/stichprobenrahmen.html. Accessed 12 Jun 2018.

24. Slimani N, et al. The standardized computerized 24-h dietary recall method EPIC-soft adapted for pan-European dietary monitoring. Eur J Clin Nutr. 2011;65(Suppl 1):S5-15.

25. Crispim SP, et al. Two non-consecutive $24 \mathrm{~h}$ recalls using EPIC-soft software are sufficiently valid for comparing protein and potassium intake between five European centres--results from the European food consumption validation (EFCOVAL) study. Br J Nutr. 2011;105(3):447-58.

26. Federal Food Safety and Veterinary Office. Swiss Food Composition Database. 2017. http://naehrwertdaten.ch/request?xml=MessageData\&xml= MetaData\&xs $=$ Start\&lan=en\&pageKey=Start. Accessed 12 Jun 2018.

27. Swiss Society for Nutrition \& Federal Food Safety and Veterinary Office. Pyramide alimentaire suisse 2011 (Swiss Food Pyramid). 2018. http://www. sge-ssn.ch/fr/toi-et-moi/boire-et-manger/equilibre-alimentaire/pyramidealimentaire-suisse/. Accessed 12 Jun 2018.

28. Souverein OW, et al. Comparing four methods to estimate usual intake distributions. Eur J Clin Nutr. 2011;65(Suppl 1):S92-101.

29. Laureano $\mathrm{GH}$, et al. Comparison of the ISU, NCI, MSM, and SPADE methods for estimating usual intake: a simulation study of nutrients consumed daily. Nutrients. 2016;8(3):166.

30. Harttig U, et al. The MSM program: web-based statistics package for estimating usual dietary intake using the multiple source method. Eur J Clin Nutr. 2011;65(Suppl 1):S87-91.

31. Kaiser HF. An index of factorial simplicity. Psychometrika. 1974;39(1):31-6.

32. Cureton EE, D'Agostino RB. Factor analysis: An applied approach. Hillsdale: L. Erlbaum Associates; 1983.

33. World Health Organization (WHO). Waist Circumference and Waist-Hip Ratio: Report of a WHO Expert Consultation. Geneva, Switzerland: WHO; 2008.

34. Schneider $\mathrm{HJ}$, et al. The predictive value of different measures of obesity for incident cardiovascular events and mortality. J Clin Endocrinol Metab. 2010; 95(4):1777-85

35. Browning LM, Hsieh SD, Ashwell M. A systematic review of waist-to-height ratio as a screening tool for the prediction of cardiovascular disease and diabetes: 0.5 could be a suitable global boundary value. Nutr Res Rev. 2010;23(2):247-69.

36. Ashwell M, Gunn P, Gibson S. Waist-to-height ratio is a better screening tool than waist circumference and BMI for adult cardiometabolic risk factors: systematic review and meta-analysis. Obes Rev. 2012;13(3):275-86.

37. World Health Organization. MONICA Manual, Part III: Population Survey, Section 1: Population Survey Data Component. 4.6 Height, weight, waist and hip measurement. 1997. http://www.thl.fi/publications/monica/manual/ part3/iii-1.htm\#s4-6. Accessed 12 Jun 2018.

38. Chiuve SE, et al. Alternative dietary indices both strongly predict risk of chronic disease. J Nutr. 2012;142(6):1009-18.

39. Hagstromer M, Oja P, Sjostrom M. The international physical activity questionnaire (IPAQ): a study of concurrent and construct validity. Public Health Nutr. 2006;9(6):755-62.

40. Craig $C L$, et al. International physical activity questionnaire: 12-country reliability and validity. Med Sci Sports Exerc. 2003;35(8):1381-95.

41. International Physical Activity Questionnaire. Guidelines for data processing and analysis of the international physical activity questionnaire - short and long forms.
2005. http://www.academia.edu/5346814/Guidelines_for_Data_Processing_and_ Analysis_of_the_International_Physical_Activity_Questionnaire_IPAQ_Short_and_ Long_Forms_Contents. Accessed 12 Jun 2018.

42. Rezagholizadeh $F$, et al. A posteriori healthy dietary patterns may decrease the risk of central obesity: findings from a systematic review and metaanalysis. Nutr Res. 2017;41:1-13.

43. Adamsson $\mathrm{V}$, et al. Role of a prudent breakfast in improving cardiometabolic risk factors in subjects with hypercholesterolemia: a randomized controlled trial. Clin Nutr. 2015;34(1):20-6.

44. Tsihlias EB, et al. Comparison of high- and low-glycemic-index breakfast cereals with monounsaturated fat in the long-term dietary management of type 2 diabetes. Am J Clin Nutr. 2000;72(2):439-49.

45. Nilsson AC, et al. Effect of cereal test breakfasts differing in glycemic index and content of indigestible carbohydrates on daylong glucose tolerance in healthy subjects. Am J Clin Nutr. 2008;87(3):645-54.

46. Jenkins DJ, et al. Viscous and nonviscous fibres, nonabsorbable and low glycaemic index carbohydrates, blood lipids and coronary heart disease. Curr Opin Lipidol. 2000;11(1):49-56.

47. Boden G. Obesity and free fatty acids. Endocrinol Metab Clin N Am. 2008; 37(3):635-46 viii-ix.

48. Rodriguez-Carrio J, et al. Free fatty acids profiles are related to gut microbiota signatures and short-chain fatty acids. Front Immunol. 2017;8:823.

49. van Rossum C, et al. Dutch National Food Consumption Survey 2007-2010. Diet of children and adults aged 7 to 69 years. Bilthoven: National Institute for public health and the environment (RIVM); 2011.

50. Almoosawi S, et al. Daily profiles of energy and nutrient intakes: are eating profiles changing over time? Eur J Clin Nutr. 2012;66(6):678-86.

51. Agence française de sécurité sanitaire des aliments (AFSSA), ed. Étude individuelle nationale des consommations alimentaires 3 (INCA 3) (3rd French Food Consumption Survey). Maisons-Alfort: AFSSA; 2017.

52. Aparicio $A$, et al. Differences in meal patterns and timing with regard to central obesity in the ANIBES ('Anthropometric data, macronutrients and micronutrients intake, practice of physical activity, socioeconomic data and lifestyles in Spain') study. Public Health Nutr. 2017;20(13):2364-73.

53. de Oliveira Santos $\mathrm{R}$, et al. Dietary patterns for meals of Brazilian adults. Br J Nutr. 2015;114(5):822-8.

54. Chatelan A, et al. Lessons Learnt About Conducting a Multilingual Nutrition Survey in Switzerland: Results from menuCH Pilot Survey. Int J Vitam Nutr Res. 2018:1-12

55. Kant AK, Graubard BI. Within-person comparison of eating behaviors, time of eating, and dietary intake on days with and without breakfast: NHANES 2005-2010. Am J Clin Nutr. 2015;102(3):661-70.

56. Sieber $\mathrm{L}$, et al. Can variability in energy intake be attributed to one meal versus another? (abstract). FASEB J. 2008. https://www.fasebj.org/doi/abs/10. 1096/fasebj.22.1_supplement.316.5.

57. Guan VX, et al. Identifying usual food choices at meals in overweight and obese study volunteers: implications for dietary advice. Br J Nutr. 2018; 120(4):472-80.

58. DeGregory KW, et al. A review of machine learning in obesity. Obes Rev. 2018;19(5):668-85.

59. Zhang $L$, et al. The Association between Breakfast Skipping and Body Weight, Nutrient Intake, and Metabolic Measures among Participants with Metabolic Syndrome. Nutrients. 2017;9(4). https://doi.org/10.3390/nu9040384.

60. Naska A, Lagiou A, Lagiou P. Dietary assessment methods in epidemiological research: current state of the art and future prospects. F1000Res. 2017;6:926.

\section{Ready to submit your research? Choose BMC and benefit from}

- fast, convenient online submission

- thorough peer review by experienced researchers in your field

- rapid publication on acceptance

- support for research data, including large and complex data types

- gold Open Access which fosters wider collaboration and increased citations

- maximum visibility for your research: over $100 \mathrm{M}$ website views per year

At $\mathrm{BMC}$, research is always in progress.

Learn more biomedcentral.com/submission 